Soft poly(N-vinylcaprolactam) nanogels surface-decorated with AuNPs. Response to temperature, light, and RF-field

Siirila, Joonas

2019-06

Siirila , J , Karesoja , M , Pulkkinen , P , Malho , J-M \& Tenhu , H 2019 , ' Soft poly(N-vinylcaprolactam) nanogels surface-decorated with AuNPs. Response to temperature, light, and RF-field ' , European Polymer Journal , vol. 115 , pp. 59-69 . https://doi.org/10.1016/j.eurpoly

http://hdl.handle.net/10138/327958

https://doi.org/10.1016/j.eurpolymj.2019.03.010

cc_by_nc_nd

acceptedVersion

Downloaded from Helda, University of Helsinki institutional repository.

This is an electronic reprint of the original article.

This reprint may differ from the original in pagination and typographic detail.

Please cite the original version. 


\section{Soft Poly(N-vinylcaprolactam) Nanogels Surface- Decorated with AuNPs. Response to Temperature, Light, and RF-field}

Joonas Siiriläa, Mikko Karesojaa, Petri Pulkkinena, Jani-Markus Malhob, Heikki Tenhua

a. Department of Chemistry, PB 55, 00014 University of Helsinki, Finland, b. Department of Applied Physics, Aalto University, Espoo, FI-00076 Finland

\section{Abstract}

Soft poly(N-vinylcaprolactam) (PNVCL) based nanogels were prepared and surface-decorated with gold nanoparticles (AuNPs). The applicability of the hybrid nanogels (PNVCL-AuNPs) as carriers for low molar mass substances was of special interest. AuNPs protected with a mixture of 11azidoundecanothiol and 11-mercaptoundecanoic acid were bound to propargyl functionalized PNVCL based nanogels. Acidic groups on the surfaces of AuNPs and PNVCL based nanogels stabilize the particle dispersions against precipitation above the phase transition temperature of PNVCL. Both the neat PNVCL nanogels and the PVCL-AuNPs shrink upon heating the dispersions. Even though the AuNPs are mainly located in the soft surface layer of the nanogels, the PNVCL-AuNPs respond to visible light as well as to radio-frequency (RF) irradiation by shrinking due to the AuNPs acting as nanoheaters. Interactions of linear PNVCL, PNVCL nanogels and PNVCL-AuNPs with two fluorescent probes were studied as function of increasing temperature. Once bound to the polymer the fluorescent probe may or may not be released from it, depending on its polarity and water solubility. Presence of AuNPs changed the release behavior of the water soluble charged fluorescent probe from the nanogels.

\section{Keywords}

Thermoresponsive, light responsive, radio-frequency responsive, vinyl lactams, water-dispersed nanogels, surface decorated particles, gold nanoparticles, cargo delivery systems. 


\section{Introduction}

Poly(N-vinylcaprolactam) (PNVCL) is a non-cytotoxic[1] polymer that exhibits temperature dependent solubility in aqueous solutions. It is an interesting building block for the development of drug delivery systems.[2-12] Properties and applications of the polymer have been extensively reported in a recent review.[13]

Linear PNVCL has a phase transition temperature i.e. a lower critical solution temperature (LCST) around $32{ }^{\circ} \mathrm{C}$ in water. The exact position of the LCST depends on the molecular weight and the concentration of the polymer. Below the LCST, PNVCL is soluble and adopts a random coil conformation in water but heating the solution above the LCST causes PNVCL to collapse in to stable mesoglobules or to precipitate, depending on the concentration. $[14,15]$

In water dispersed crosslinked PNVCL nanogels, the dissolution of the polymer to individual linear chains is prevented by the crosslinks, and the thermal transition is referred to as a volume phase transition (VPT).[3, 5, 6, 10,13,16-21] Below the VPT the nanogel is swollen with water due to the polymer being soluble. Upon heating, the nanogels expel water from their polymer network. Whether the shrunken nanogels precipitate or not depends on the effectiveness of their stabilization. The volume phase transition may be used to release loaded compounds from the gels. Compounds studied so far include 5-fluorouracil[3, 6], doxorubicin[5, 10], curcumin[7, 8], nadolol,[12] propranolol[12] and tacrine[12].

Acidic groups ( $\mathrm{pH}$ sensitive) and reducible crosslinks have been incorporated in to PNVCL nanogels to maximize the release of drugs in cancerous tissue. $[3,5,10]$ Temperature change, $\mathrm{pH}$ difference and the presence of reductants are regarded as internal triggers. Another approach is to use functionalities that respond to external triggers such as applied magnetic field or radiation.

In this work, the latter approach has been utilized. The incorporation of AuNPs to the PNVCL nanogels turns the nanogels sensitive to electromagnetic radiation. Small AuNPs can be heated via light[22] or radiofrequency radiation (RF) $[7,23,24]$. Heating of the AuNPs on the PNVCL nanogels via radiation is expected to cause the nanogels to shrink, even when the AuNPs are bound to the surfaces of the nanogels. Urtti et al. have used the approach to release calcein from liposomes via heating $2 \mathrm{~nm}$ AuNPs with UV.[22] Jayakumar et al. released curcumin from chitosan-g-PNVCL particles via heating AuNPs with RF.[7] 
There is a synergetic effect of using metallic nanoparticles as part of a therapeutic solution as metal nanoparticles are also effective bioimaging agents, for example providing X-ray contrast.[25, 26] Thus, in principle the accumulation of the hybrid particles to a certain site may be followed and this information used to decide the right time to trigger the AuNP heating.

Effective synthesis protocols for PNVCL nanogels including the effect of varying different parameters, as well as suitable analysis methods for such particles are well established in literature.[3, 5, 6, 10, 13, 17-20] Water dispersed PNVCL nanogles are synthesized via radical polymerization in water above the LCST of the polymer. Insoluble polymers collapse and aggregate to form particles during the polymerization. Stabilizer is used to keep the particles dispersed and to control the size of the particles. Stabilizer is either a surfactant,[5, 6, 10, 17-19], a polymerizable surfactant,[20], comonomer[3] or a reactive macromolecular additive [27]. The process is either precipitation/dispersion or emulsion polymerization, depending on the concentration used in the synthesis. A crosslinker is used in the feed to obtain permanent covalently crosslinked particles. The effects of the crosslinker type and concentration, surfactant concentration, and polymerization temperature, on the nanogels properties have been studied by Forcada et al.[17-19]

In the current work, published synthesis procedures were adopted and modified for the synthesis of alkyne functionalized PNVCL-based nanogels. It has been shown that acrylate or methacrylate comonomers polymerize faster than $\mathrm{N}$-vinylcaprolactam due to higher reactivity.[17] This is why we used a semi-batch process to enrich the nanogel surface with alkyne containing acrylate monomer, propargyl acrylate. This method of polymerizing a second monomer to the shell of a first polymerized core particle via semibatch polymerization has been extensively utilized in emulsion polymerization to produce core/shell copolymer particles. [28]

The alkyne containing PNVCL-based nanogels were decorated with $2.8 \mathrm{~nm}$ azide and carboxylic acid functional, water-dispersable gold nanoparticles (AuNPs) via $\mathrm{Cu}(\mathrm{I})$ catalyzed azide-alkyne cycloaddition (CUAAC). The method has been previously used to react particles with small azides.[29, 30] Here we use the approach to link particles to nanogels.

Hydrogel nanoparticles containing AuNPs have been previously reported where the polymer has been PNIPam,[31, 32] PNVCL,[33, 34] or PNVCL-g-chitosan[7]. In most cases, however, AuNPs have been synthesized via direct reduction of auric acid inside the gels.[31-34] The method is simple but the size of the particles is controlled by the media (the gel) allowing less variation compared to the approach where AuNPs are synthesized separately and then attached to the gel particles. We synthesized the 
AuNPs with Brust-Schiffrin method[35] and attached them to the gel surfaces via click chemistry. AuNPs prepared via this method are small $(1.5$ to $5.2 \mathrm{~nm}$ ) and protected by thiol ligands. The ligands covering the Au surface render it less catalytically active, $[36,37]$ and the chemical inertness may be important in biomedical applications, when the catalytic function is not intended. The synthesis method also allows attachment of targeting ligands on to the AuNPs. The method is distinctly different from the ones utilized earlier, where preformed nanoparticles have been incorporated to PNVCL nanogels. These methods include the synthesis of the nanogels in presence of nanoparticles to be incorporated [38, 39] and loading of nanoparticles to nanogels via solvents exchange [40] or solvent exchange accompanied with ligand exchange [41]. In these techniques the nanoparticles are expected to be buried inside the nanogels.

AuNPs were prepared by protecting them with mixtures of mercaptoundecanoic acid and azidounecanethiol. The acid was needed to stabilize the AuNPs in water. The azido functional AuNPs were clicked to the propargyl functional nanogels to obtain responsive nanogels with AuNPs enriched on their surfaces. Whereas several studies have been conducted on gels where AuNPs were buried in the gel structure, our aim was to see how effectively one may control the volume phase transition of a nanogel by heating the gel surface.

The success of the conjugation of AuNPs to the nanogels via CuAAc was confirmed via FT-IR and with cryo-TEM imaging. The sizes of the hybrid AuNP-PNVCL gel particles were studied with dynamic light scattering as a function of temperature and as a function of light exposure and RF irradiation.

To test the possibility of using the nanogels as functional carriers, interactions of the nanogels with fluorescent probes were studied with steady-state fluorescence spectroscopy. The chosen probes are sensitive to the polarity and to the microviscosity of their surroundings, allowing the intricate effect of volume phase transition to be studied in detail. 


\section{Experimental}

\section{Materials:}

All reagents were from Sigma Aldrich and used as such if not stated otherwise. Methacrylic acid (MAA) and propargyl acrylate (PA) were passed through an inhibitor remover resin (Sigma). VCL was recrystallized from toluene. 11-azidoundecanothiol (AZT)[42] and N,N'-bis(acryloyl)cystamine (BAC)[43] were synthesized according to literature. Synthesis details and product analysis via ${ }^{1} \mathrm{H}-\mathrm{NMR}$ are presented in Supplementary materials.

Buffers used include: 0.1 M HEPES buffer (4-(2-hydroxyethyl)-1-piperazineethanesulfonic acid), $\mathrm{pH}=7.4), 0.1 \mathrm{M}$ acetate $(\mathrm{pH}=5.5)$ and $0.1 \mathrm{M}$ phosphate buffer $(\mathrm{pH}=7.4)$.

Distilled water was used in all experiments.

\section{PNVCL nanogel synthesis}

PNVCL particles were prepared via precipitation polymerization. N-VCL $1.880 \mathrm{~g}$, MAA $0.020 \mathrm{~g}$, BAC $0.020 \mathrm{~g}$, sodium dodecyl sulfate (SDS) $0.050 \mathrm{~g}$ and $\mathrm{NaHCO}_{3} 0.050 \mathrm{~g}$ were weighted in flask and dissolved in $196 \mathrm{~g}$ of water. The flask was flushed 30 min with of $\mathrm{N}_{2}$ gas at room temperature and then transferred to a preheated oil bath for 30 minutes for the reaction mixture to heat to $70{ }^{\circ} \mathrm{C}$. Separately the initiator potassium persulfate (KPS) $0.050 \mathrm{~g}$ was dissolved in $4 \mathrm{~g}$ of water and flushed with $\mathrm{N}_{2}$ gas for $20 \mathrm{~min}$. Reaction was started by adding the KPS solution to the reaction flask. The mixture turned turbid within 5 minutes. After $1 \mathrm{~h}, 0.100 \mathrm{~g}$ of PA was added as a comonomer to the reaction flask and allowed to react for $22 \mathrm{~h}$ at $70^{\circ} \mathrm{C}$. The reaction mixture was purified by dialysis (MWCO 12-14 00 g/mol) against water. Next, the dispersion was freeze dried to obtain dry product. Mass of pure product was $0.988 \mathrm{~g}$.

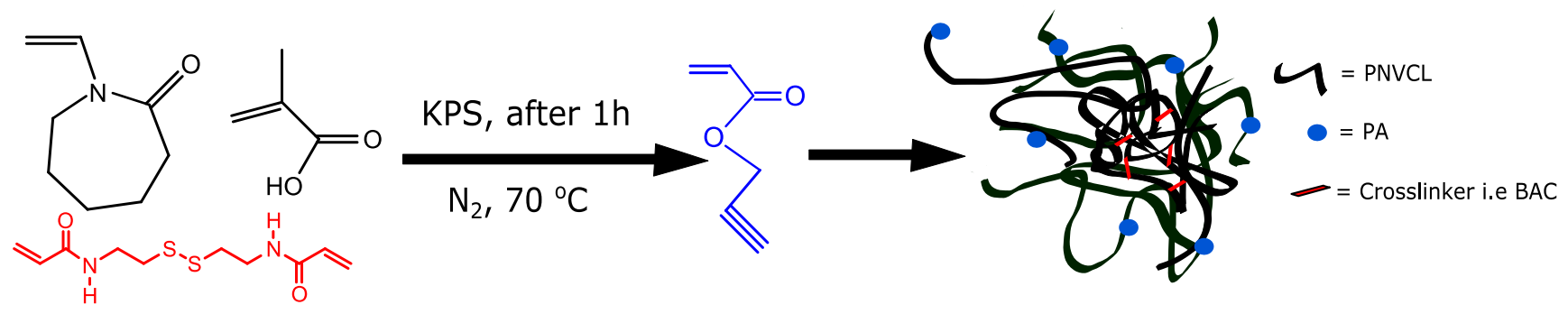

Figure 1. Synthesis of PNVCL nanogels 


\section{AuNP synthesis}

Particles were prepared via modified Brust-Schiffrin method.[35] $\mathrm{HAuCl}_{4}(1.5 \mathrm{mmol})$ was dissolved in 10 $\mathrm{mL}$ of water and added to a vigorously stirred solution of tetraoctylammonium bromide $(3.8 \mathrm{mmol})$ in toluene $(118 \mathrm{ml})$. The organic phase containing the gold was separated. Butanethiol $(1.53 \mathrm{mmol})$ was added and the solution was mixed for $10 \mathrm{~min}$ in room temperature. $\mathrm{NaBH}_{4}(5.4 \mathrm{mmol})$, dissolved in 10 $\mathrm{ml}$ of water, was added as a single shot with $1 \mathrm{ml} / \mathrm{s}$ speed. Reaction time was $3 \mathrm{~h}$. The organic phase was collected, and the solvent was concentrated in a rotary evaporator. The black product was suspended in $30 \mathrm{~mL}$ of ethanol, collected on a glass filtration frit (porosity 5), and washed with at least $80 \mathrm{~mL}$ of ethanol and $150 \mathrm{~mL}$ of acetone. The particles were obtained from the frit by adding tetrahydrofuran.

Ligand exchange was performed to get clickable thiol protected AuNPs. Ligands, 11-azidoundecanothiol (AZT) $1.5 \mathrm{mmol}$ and 11-mercaptoundecanoic acid (MUA) $4.5 \mathrm{mmol}$ were added to the tetrahydrofuran dispersion and the mixture was stirred at room temperature for one week. Purification after concentrating by addition to toluene and precipitation onto a frit. AuNPs were collected by passing ethanol through the frit. Particles were analyzed with ${ }^{1} \mathrm{H}-\mathrm{NMR}, \mathrm{TGA}$ and cryo-TEM. TGA mass loss in $\mathrm{N}_{2}$ flow from 20 to $500{ }^{\circ} \mathrm{C}$ was $24 \%$. Yield in gold was $32 \%$. ${ }^{1} \mathrm{H}$-NMR was used to determine the real ligand composition after detaching ligands from AuNPs with $\mathrm{I}_{2}$.[44] The particles were stored at $-19^{\circ} \mathrm{C}$, dispersed in ethanol.

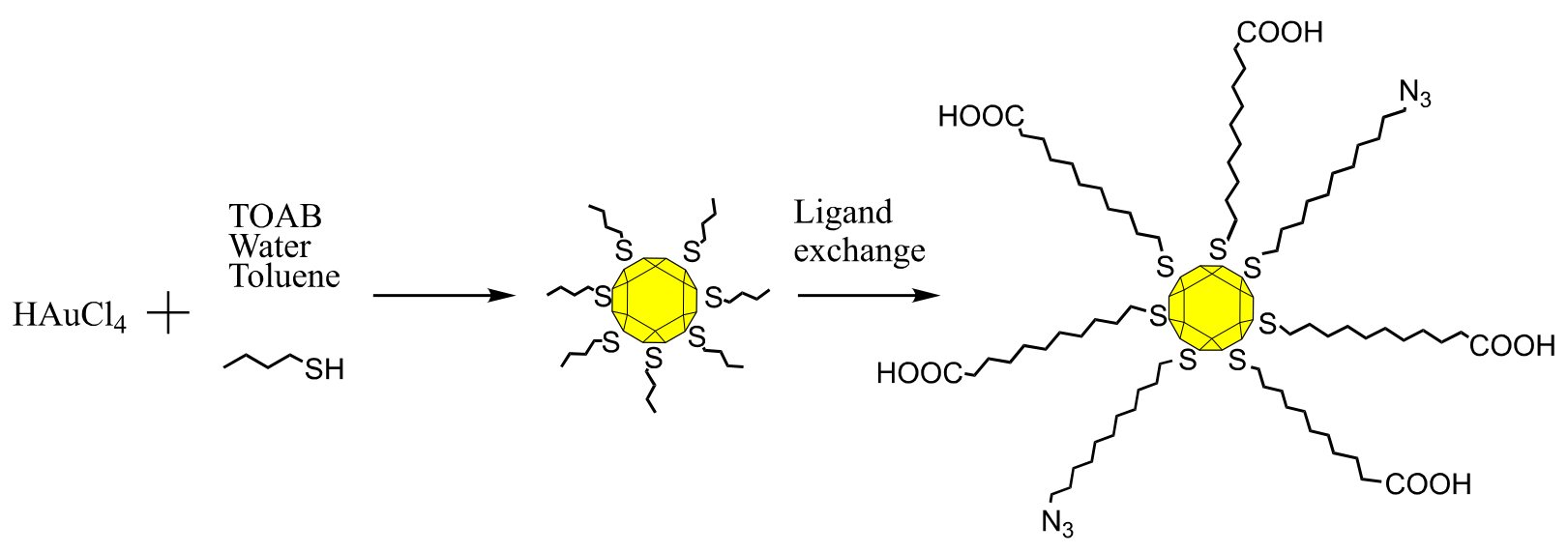

Figure 2. Synthesis of precursor AuNPs, followed by ligand exchange to obtain the (clickable) AuNPs 


\section{Synthesis of PNVCL-AuNPs via CuAAC}

$5 \mathrm{mg}$ of AuNPs dispersed in $2 \mathrm{ml}$ of ethanol were added to a mixture of $20 \mathrm{mg}$ PNVCL in $20 \mathrm{ml} 0.1 \mathrm{M}$ phosphate buffer $(\mathrm{pH}=7.4)$. The dispersion was flushed with nitrogen for $1 \mathrm{~h}$ prior to the addition of 4.8 $\mathrm{g}$ of $\mathrm{Cu}(\mathrm{OAc})_{2}$ hexahydrate dissolved in $1 \mathrm{ml}$ of $\mathrm{H}_{2} \mathrm{O}$, and $20 \mathrm{mg}$ of sodium ascorbate also dissolved in $1 \mathrm{ml}$ of $\mathrm{H}_{2} \mathrm{O}$ to start the reaction. Reaction was continued $46 \mathrm{~h}$ under protective atmosphere. The dispersion was diluted with water containing disodium salt of ethylene diamine tetra-acetic acid (EDTA) and dialyzed against pure water for 3 days to remove copper. After dialysis, unstable particles were removed via centrifugation at $15^{\circ} \mathrm{C}$ for $15 \mathrm{~min} 5000 \mathrm{rpm}$. The $60 \mathrm{ml}$ dispersion was extracted with 70 $\mathrm{ml}$ of dichloromethane (DCM). $\mathrm{NaCl}$ was added to the water phase to give $0.1 \mathrm{M}$ solution and extraction was done again with $70 \mathrm{ml}$ of DCM. Now product was in DCM phase and DCM phase was washed with $\mathrm{H}_{2} \mathrm{O}, 0.1 \mathrm{M}$ phosphate buffer and $0.1 \mathrm{M}$ acetic acid. After washing, the DCM phase was concentrated and diluted with ethanol 3 times to replace DCM with ethanol. Then ethanol was exchanged to $\mathrm{H}_{2} \mathrm{O}$ via dialysis. The dispersion was concentrated to give $12.5 \mathrm{ml}$ of $1 \mathrm{mg} / \mathrm{ml}$ dispersion as a product. Part of the dispersion was freeze-dried for TGA measurements.

\section{Cryo-TEM imaging of PNVCL-AuNP particles}

PNVCL-AuNPs were analyzed using JEM 3200FSC cryo-transmission electron microscope (Jeol) operated at $300 \mathrm{kV}$ in bright field mode. Images were acquired with a CCD camera (Gatan) using an Omega-type Zero-loss energy filter, while the specimen temperature was kept at $-187^{\circ} \mathrm{C}$. Vitrified samples were prepared using FEI Vitrobot Mark IV by placing $3 \mu \mathrm{L}$ sample solution on 400 mesh lacey or holey carbon copper grids under $100 \%$ humidity, then blotted two times with filter paper for 1.5-2.5 s and subsequently plunged into $-170^{\circ} \mathrm{C}$ ethane/propane mixture. The vitrified samples were then cryotransferred to the microscope. Size of AuNPs was analyzed from the images using ImageJ software. The average size was calculated based on over 1000 AuNPs measured.

\section{TGA}

Measurements were performed with Mettler Toledo TGA 850 under nitrogen atmosphere (flow rate 50 $\mathrm{ml} / \mathrm{min}$ ) at heating rate $10^{\circ} \mathrm{C} / \mathrm{min}$ in the temperature range from $25^{\circ} \mathrm{C}$ to $800^{\circ} \mathrm{C}$. Sample mass was 3.5-4 mg and measurements were performed using $70 \mu \mathrm{l} \mathrm{Al}_{2} \mathrm{O}_{3}$ crucibles. 
IR

IR-spectra of dry samples were measured with FT-IR spectrometer One form PerkinElmer using an ATR sample head. The samples were placed as ethanol dispersions on top of the measurement diamond and dried.

\section{${ }^{1} \mathrm{H}-\mathrm{NMR}$}

All NMR experiments were performed with a $500 \mathrm{MHz}$ Bruker Avance III spectrometer at $23^{\circ} \mathrm{C}$.

\section{DLS}

Two types of instrumentation were used. Stability of dispersions against heating was studied with Malvern Instruments ZetaSizer Nano-ZS equipped with a $4 \mathrm{~mW}$ He-NE laser operating at $633 \mathrm{~nm}$. Hydrodynamic diameters were measured at $173^{\circ}$. Measurements were carried out in the temperature range $16-61{ }^{\circ} \mathrm{C}$ with $3{ }^{\circ} \mathrm{C}$ steps. The samples were equilibrated for $15 \mathrm{~min}$ at each temperature. Hydrodynamic diameter is given as intensity average, and intensity is given as counts per second.

Effect of light and RF exposure on the size of PNVCL particles was measured using a Brookhaven instrument BI-200SM goniometer, BIC-TuboCorr digital pseudo-cross-correlator and BI-CrossCorr detector including two BIC-DS1 detectors. Pseudo-cross-correlation functions were collected in a selfbeating method. Light source was BI-mini L140 at $637 \mathrm{~nm}$, operated with 50\% power, incident light 70 $\mathrm{mW}$. The sample cell was controlled with a Lauda RC 6 CP thermostat and the temperature was kept at $22^{\circ} \mathrm{C}$.

Sample concentration was $0.25 \mathrm{mg} / \mathrm{ml}$.

\section{Effect of light irradiation - DLS}

The source used for light exposure was Ivoclar Vivadent - Bluephase 20i LED lamp with 385-515 nm wavelength $2-2.2 \mathrm{~W} / \mathrm{cm}^{2}$. $0.3 \mathrm{ml}$ of $0.25 \mathrm{mg} / \mathrm{ml}$ sample solution was placed in an NMR cuvette and radiated with the turbo mode for $30 \mathrm{~s}$. After light exposure cuvette was placed in the light scattering device and size was measured at $90^{\circ}$ angle $10 \mathrm{~s}$ after light exposure, in a $30 \mathrm{~s}$ measurement. The measurement was repeated 3 times with 30 min intervals and combined to give a correlation function. 


\section{Effect of radiofrequency irradiation -DLS}

Cesar 1312 RF-generator connected to VM 1000-1500 automatching unit was used to create 13.56 $\mathrm{MHZ}$ oscillating electric field between two Teflon tape covered metal plates, $14 \mathrm{~mm}$ distance between the plates. Oscilloscope was used to determine the potential difference between the plates, which was $121.6 \mathrm{~V}$. Electric field strength was then $8.7 \mathrm{kV} / \mathrm{m}$. Typically $5 \mathrm{~min}$ radiation times were used, followed by $20 \mathrm{~s}$ period, when the quartz cuvette with $1 \mathrm{~cm}$ path length was used in the measurements. $1.3 \mathrm{ml}$ of $0.25 \mathrm{mg} / \mathrm{ml}$ samples, were placed in cuvette and radiated for $5 \mathrm{~min}$. After RF radiation, the cuvette was placed in the light scattering device $20 \mathrm{~s}$ after the light exposure and size was measured in a $30 \mathrm{~s}$ measurement. The measurement was repeated 3 times with 30 min intervals and combined to give a correlation function.

\section{Fluorescence spectroscopy}

Fluorescence emission spectra were recorded with a Horiba Jobin Yvon Fluoromax-4 spectrofluorometer. Quartz cuvettes with $10 \mathrm{~mm}$ path length were used.

Fluorescence was used to study the volume phase transition of PNVCL-AuNP upon heating. Two probes were used: 8-anilino-1-naphtalenesulfonic acid (ANS) and 4-(dicyanomethylene)-2-methyl-6-(4dimethylaminostyryl)-4H-pyran (4HP). The structures of ANS and 4HP are shown in Figure 3. Emission spectra were measured at different temperatures ranging from 16 to $73^{\circ} \mathrm{C}$ in 3 degree intervals, after 15 min of stabilization at each temperature.

ANS samples were prepared from $2 \mathrm{ml} 0.25 \mathrm{mg} / \mathrm{ml}$ polymer in $10 \mathrm{mM}$ HEPES solutions by adding $2 \mu \mathrm{L}$ of $10 \mathrm{mM}$ ANS aqueous solution and mixing overnight. Emission was measured with $379 \mathrm{~nm}$ excitation using $1 \mathrm{~nm}$ excitation and $2 \mathrm{~nm}$ emission slits. Blank measurements were performed with samples before additions of the fluorescent probe and this data was subtracted from the sample spectra.

4HP samples were prepared by adding $6.6 \mu \mathrm{L}$ of $10 \mathrm{mM} 4 \mathrm{HP}$ chloroform solutions to empty vials, which were then dried under nitrogen flow. $2 \mathrm{ml}$ of $0.25 \mathrm{mg} / \mathrm{ml}$ polymer in HEPES solution was added to the vials and the solutions were kept in refrigerator for at least 2 days prior to measurements. For 4HP, fluorescence emission was measured with $470 \mathrm{~nm}$ excitation using $1 \mathrm{~nm}$ excitation and $2 \mathrm{~nm}$ emission slit widths.

Anisotropy measurements on 4HP samples were performed using $470 \mathrm{~nm}$ excitation and emission was observed at $595 \mathrm{~nm}$. Slit width values were $5 \mathrm{~nm}$ for both excitation and emission for PNVCL and $7 \mathrm{~nm}$ for PNVCL-AuNPs. 
<smiles>O=S(=O)(O[Na])c1cccc2cccc(Nc3ccccc3)c12</smiles><smiles>CC1=CC(=C(C#N)C#N)C=C(/C=C/c2ccc(N(C)C)cc2)O1</smiles>

Figure 3. Fluorescent probes, 8-anilino-1-naphtalenesulfonic acid ammonium salt (ANS) on left and 4(dicyanomethylene)-2-methyl-6-(4-dimethylaminostyryl)-4H-pyran (4HP) on right

\section{Results and discussion}

\section{PNVCL nanogel characteristics}

The gel particles were characterized through IR spectroscopy and by measuring the particle size at different temperatures. IR spectra of the PNVCL nanogel is presented in Figure 4. and the assigned peaks are listed in Table 1. All of the characteristic spectral lines of PNVCL[45] are seen in the spectra. A band from the carbonyl group of propargylacrylate at $1731 \mathrm{~cm}^{-1}$ indicates a successful incorporation of the alkyne bearing monomer to the nanogels.

The nanogels dispersed in $10 \mathrm{mM}$ HEPES buffer exhibited thermoresponsive behavior. The z-average hydrodynamic diameters measured with dynamic light scattering at $173^{\circ}$ are plotted against temperature in Figure 5. The z-average hydrodynamic diameter of the PNVCL particles was $220 \mathrm{~nm}$ at $16^{\circ} \mathrm{C}$ and decreased to $150 \mathrm{~nm}$ when heated to $61^{\circ} \mathrm{C}$. As can be seen, the thermal collapse started right at the start of the heating, indicating the presence of the hydrophobic propargyl moieties on the surfaces. 
Table 1. IR peaks

\begin{tabular}{|l|l|l|l|}
\hline \multirow{2}{*}{ Functional group } & \multicolumn{3}{|c|}{ Wavenumber $\left(\mathrm{cm}^{-1}\right)$} \\
\cline { 2 - 4 } & \multicolumn{1}{|c|}{ PNVCL nanogel } & $\begin{array}{c}\text { PNVCL-AuNP hybrid } \\
\text { nanogel }\end{array}$ & \multicolumn{1}{c|}{ AuNP } \\
\hline $\mathrm{OH}$ & 3500 & 3500 & \\
\hline $\mathrm{NH}$ & 3272 & 3272 & $3500-2500$ \\
\hline $\mathrm{COOH}$ & & & 2923,2855 \\
\hline$-\mathrm{CH}_{2-}$ & 2923,2855 & 2923,2855 & 2095 \\
\hline$-\mathrm{N}_{3}$ & & & 1709 \\
\hline $\mathrm{C}=\mathrm{O}$ ester & 1731 & 1731 & 1470,1413 \\
\hline $\mathrm{C}=\mathrm{O}$ amide & 1634 & 1634 & \\
\hline $\mathrm{C}=\mathrm{O}$ acid & & & $1470,1422,(1442)$ \\
\hline$-\mathrm{CH}_{2-},\left(-\mathrm{CH}_{2}-\mathrm{C} \equiv \mathrm{C}\right)$ & $1470,1422,(1442)$ & \multicolumn{2}{|c|}{} \\
\hline
\end{tabular}

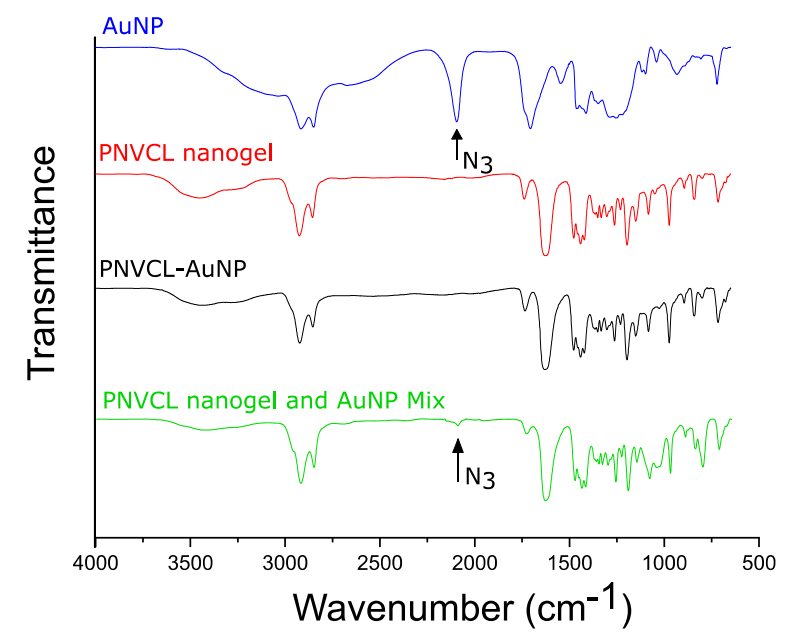

Figure 4. IR-spectra of AuNPs, PNVCL nanogel, PNVCL-AuNPs and PNVCL nanogel 75wt\% AuNP 15 wt\% mixture 


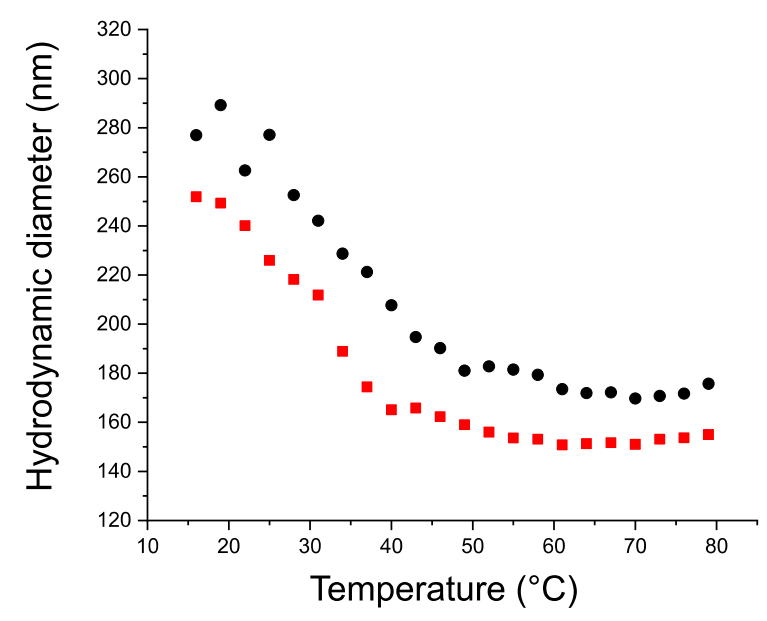

Figure 5. Hydrodynamic diameter (intensity mean average) vs. temperature for $\square$ PNVCL nanogels, PNVCL-AuNP nanogels, in $10 \mathrm{mM} \mathrm{HEPES} \mathrm{pH}=7.4$

\section{AuNP characteristics}

The synthesized AuNPs were protected with a mixture of ligands of 11-azidoundecanethiol (AZT) and 11-mercaptoundecanoic acid (MUA). First, the stability AuNPs in aqueous dispersion was studied. The carboxylic acid end group of MUA render the AuNPs water dispersible at $\mathrm{pH} \geq 6.1$. Stability test was performed by dispersing $0.25 \mathrm{mg}$ of gold nanoparticles to acetate or phosphate buffer (buffer concentration $100 \mathrm{mM}$ ) of a known $\mathrm{pH}$ and storing a week at room temperature, followed by visual inspection of stability. A picture of the dispersions is presented in Figure 6.

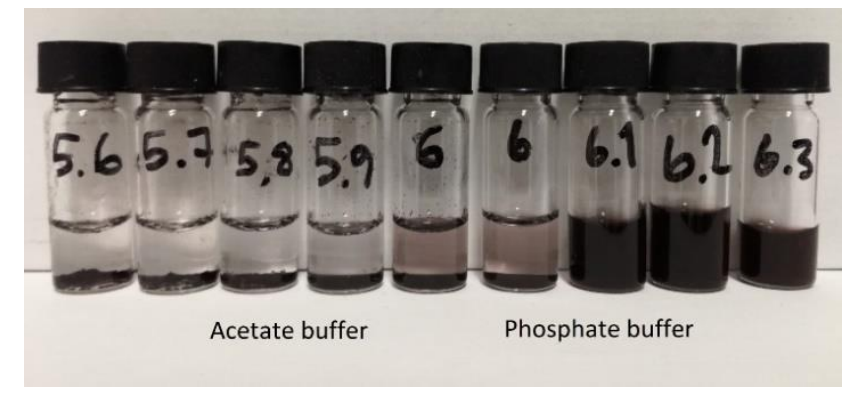

Figure 6. Stability of ligand protected AuNPs as a function of $\mathrm{pH}(\mathrm{pH}$ written on the vial) 
Secondly, the ligand composition on the gold nanoparticles was analyzed via ${ }^{1} \mathrm{H}-\mathrm{NMR}$, measured in deuterated THF after detachment of ligands with $\mathrm{I}_{2}$ (for details see $\mathrm{SI}$ ). The ligand composition of AuNPs was $76 \mathrm{~mol} \%$ of MUA and $24 \mathrm{~mol} \%$ of AZT, which closely corresponds to the ligand composition used in the synthesis (75\% MUA and 25\% AZT).

Thermogravimetric analysis was used to determine the weight percentage of organic compounds i.e the ligands on the AuNPs. Thermograms are presented in Figure 7. The ligand content of AuNPs was found to be $24 \mathrm{wt} \%$.

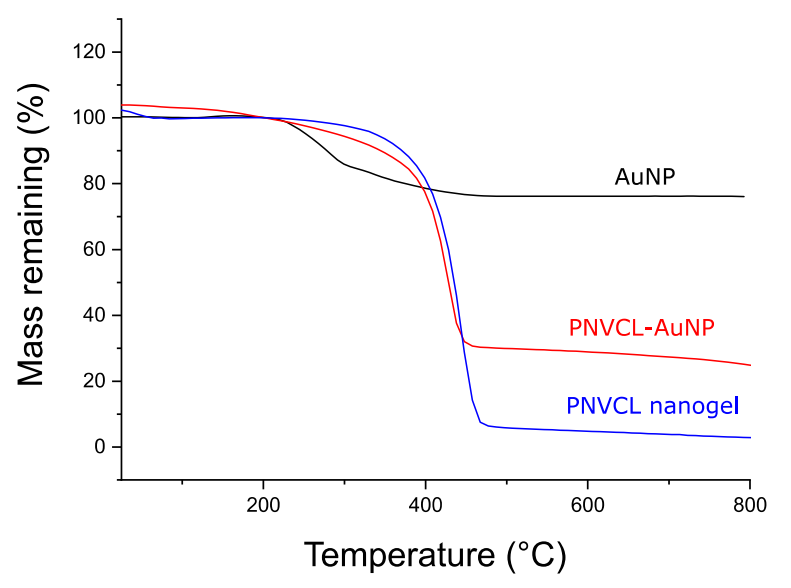

Figure 7. Thermograms of ligand protected AuNPs, PNVCL-AuNPs, and PNVCL.

Thirdly, the size of the AuNPs was analyzed based on cryo-TEM images of the PVCL-AuNPs (see SI, Figures S2 and S3). The average diameter of AuNPs was found to be $2.8 \mathrm{~nm}$ with $0.4 \mathrm{~nm}$ standard deviation (for details see SI). Based on literature, the expected shape of the particles is a truncated octahedron.[35, 46, 47] Assuming the truncated octahedron shape, volume of an average particle can be calculated using the diameter obtained from cryo-TEM analysis. [48] From the calculated volume and using density of gold (59.006 1/nm $\mathrm{nm}^{3}$, calculated from bulk density of gold), the number of Au atoms per AuNP can be calculated. Based on the calculations, a $2.8 \mathrm{~nm}$ AuNP contains $473 \mathrm{Au}$ atoms. From the TGA measurements we know the mass ratio of ligands to Au in the AuNPs and thus, there number of ligands per particle is 133. From the ligands 33 are AZT and 100 MUA (calculated based on the ratio determined via NMR). The chemical formula of the AuNPs is thus $\mathrm{Au}_{473} \mathrm{MUA}_{100} \mathrm{AZT} \mathrm{T}_{33}$ 
Last, the position of the surface plasmon resonance (SPR) of the AuNPs dispersed in ethanol and in 10 $\mathrm{mM}$ aqueous HEPES, was determined via UV-vis spectroscopy. UV-Vis-Spectra are shown in Figure 8. SPR peak found to be at $522 \mathrm{~nm}$ in ethanol and at $528 \mathrm{~nm}$ in $10 \mathrm{mM}$ HEPES. The peak position is influenced by the size and shape of the particle, as well as by the dielectricity of the medium.[49] The peak maxima may seem high for such a small particle.[50] However, the values support the assumption of the truncated octahedral shape of the AuNPs. Truncation of a shape has been shown to be accompanied with a red-shift and broadening of the LSRP peak for metal nanoparticles.[49]

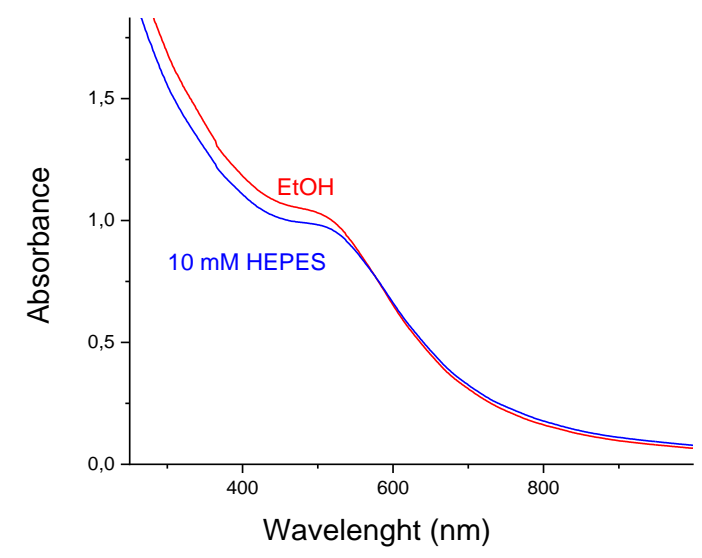

Figure 8. UV-Vis spectra of $0.125 \mathrm{mg} / \mathrm{ml}$ ligand protected AuNPs in ethanol and in $10 \mathrm{mM}$ HEPES

\section{PNVCL-AuNP characteristics}

AuNP content of the PNVCL-AuNPs was determined based on TGA measurements (Figure 7). Based on calculations, presented in Supplementary materials, there was $30 \mathrm{wt} \%$ of AuNPs in the hybrid particles. The value is relatively close to the amount used in the feed (20 wt\%). The presence of AuNPs in the hybrid particles was confirmed also with naked eye (dark red color), with UV, and with cryo-TEM (Figure 9) as will be shown below.

In the IR spectrum of the PNVCL-AuNPs, all bands of PNVCL are seen (Figure 4). Surprisingly, despite the relatively large amount of AuNPs in the hybrid particles (30 wt\%) no bands from the AuNP ligands are seen in the spectrum. To compare, a spectrum made from a mixture of AuNPs and PNVCL nanogel particles ( $25 \mathrm{wt} \%$ of AuNPS) was also measured and is presented in Figure 4 . In the IR spectrum of the mixture, peaks arising from ligands on the AuNPS are mostly overlapped by the bands of PNVCL 
nanogel, but the peak from azide is clearly observable at $2095 \mathrm{~cm}^{-1}$. This peak is naturally not seen in the spectrum of the hybrid as the azides have reacted in the click reaction.

Based on the cryo-TEM (Figure 9), the average diameter of a PNVCL nanogel is $130 \mathrm{~nm}$ with a $25 \mathrm{~nm}$ standard deviation. The size is considerably smaller than the size obtained with DLS (230 $\mathrm{nm}$ ). The cryo-TEM images, are seen to reveal the denser core of the nanogels and the AuNPs, leaving out the less dense shell PNVCL due to insufficient contrast. Based on literature, PNVCL nanogel generally have a denser, more crosslinked core and a looser shell with dangling chains.[17, 21] More Cryo-TEM images are presented in Supplementary materials (Figure S2 and S3).

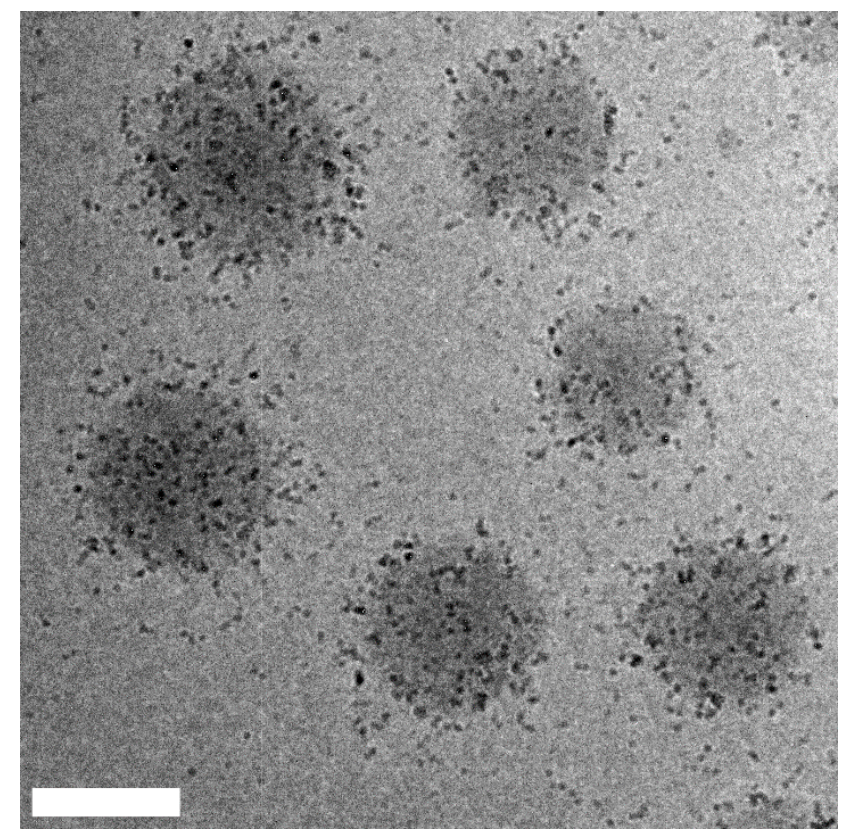

Figure 9. Cryo-TEM image of hybrid PNVCL-AuNP particles (100 nm scale bar)

The PNVCL-AuNPS exhibit thermoresponsive behavior in $10 \mathrm{mM}$ HEPES buffer as seen from the dynamic light scattering data measured at scattering angle $173^{\circ}$ and presented in Figure 5. Compared to the neat PNVCL nanogels, the PNVCL-AuNPs are bigger at all temperatures. The difference arises from the hydrophilic character of AuNPs at the measuring $\mathrm{pH}(7.4)$ and is consistent with the observed increase of the hydrodynamic size when a charged comonomer is used in the synthesis of nanogel particles.[5, 10] It should however be noted that the PNVCL-AuNPs had bimodal size distribution according to the measurements made at $90^{\circ}$ (Figure 10 and 11). Similar bimodality was not observed with neat PNVCL nanogels (Figure 10 and 11). This bimodality is likely to cause a certain inaccuracy in the mean size values presented in Figure 5. 
Additional experiments were conducted to find out the origin of the bimodal size distribution. Originally, our purpose was to synthesize polymer particles, which are solely crosslinked with disulfide bonds. It turned out, however, that during the polymerization "extra" crosslinks built up. To our disappointment we were not able to break the particles by reducing the -S-S- bridges. Neat PNVCL gel particles were reduced with sodium ascorbate and the particle size was followed, see Supplementary materials (Figure S7). The reduction of the disulfide bridges produced large loosely crosslinked nanogels but also smaller particles. Because sodium ascorbate is used also in the click reaction we conclude that the nanogel particles get both slightly swollen and partially degrade during the attachment of AuNPs via the click reaction. The bimodality was not observed in the cryo-TEM images, but in cryo-TEM only few particles are analyzed compared to a statistical method like light scattering. In the following, we show the sizes measured at $90^{\circ}$ angle.

\section{Light exposure}

The effect of light irradiation on the samples is seen by comparing the hydrodynamic diameters before and after the irradiation. The hydrodynamic diameter distributions obtained from measurements at $90^{\circ}$ are shown in Figure 10 for $0.25 \mathrm{mg} / \mathrm{ml}$ PNVCL nanogel and PNVCL-AuNPs in $10 \mathrm{mM} \mathrm{HEPES.} \mathrm{Blue}$ light radiation $\left(\max .2 \mathrm{~W} / \mathrm{cm}^{2}\right)$ did not affect the size distribution of neat PNVCL nanogels but made PNVCL-AuNPs shrink. In case of PNVCL-AuNPs, the diameter of smaller nanogels decreased $42 \%$ and that of the bigger ones only $16 \%$.
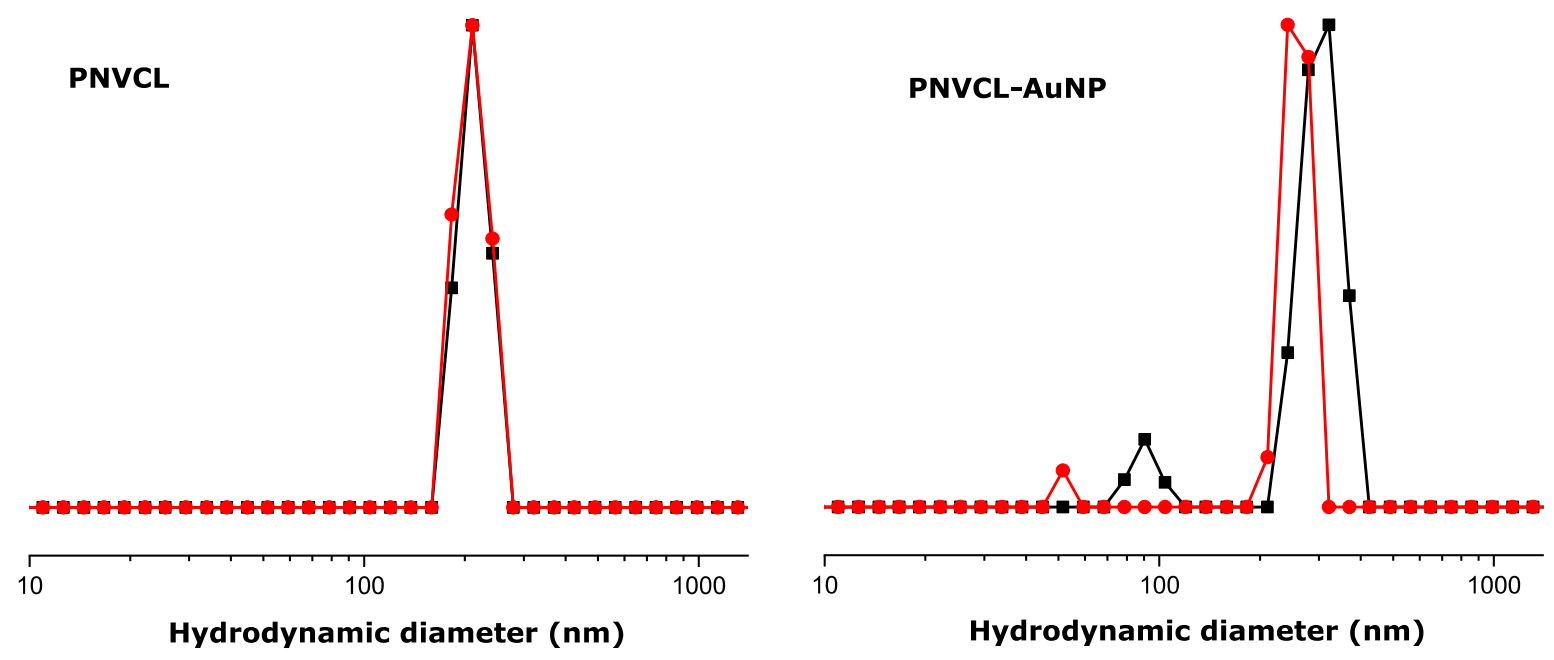

Figure 10 . Hydrodynamic radius before $(\boldsymbol{\bullet})$ and after $(\bullet) 30$ s of LED exposure for the nanogels; PNVCL on left and for PNVCL-AuNPs on right. 


\section{Effect of radiofrequency radiation}

13.52 $\mathrm{MHz}$ radiofrequency radiation source was connected to a parallel-plate capacitor to create an oscillating electric field between the plates. An oscilloscope was used to measure the maximum potential difference between plates, which was $121.6 \mathrm{~V}$. Knowing the distance between the plates, it was calculated that the electric field strength was $8.7 \mathrm{kV} / \mathrm{m}$. 5 min exposure in the field was sufficient to cause the shrinkage of PNVCL-AuNPs. The hydrodynamic diameters before and after RF exposure are presented in Figure 11. Diameter of the smallest PVCL-AuNPs decreased $47 \%$, while the diameter of the bigger PVCL-AuNPs decreased only $23 \%$. A small difference in size was also measured for the neat PNVCL nanogels, as their hydrodynamic diameter decreased $11 \%$ after 5 min exposure, indicating that the PNVCL nanogels also themselves, in absence of AuNPs, generate heat in an oscillating electric field. There has been a debate on the mechanism of the heating of AuNPs in 13.56 MHz oscillating electric field. [23, 24, 51]. Current hypothesis suggests that the heating is due to movements and collisions of charged objects in an oscillating field. This type of heating is not specific to AuNPs but affects all charged objects and can be used to explain also the heating of the neat PNVCL nanogels (charges from MAA comonomer and initiator). In addition, it was observed that our RF systems also induced heat in simple saline solutions. This observation has been confirmed also by others. $[7,23,51]$ The strength of electric field was selected such that be a maximum difference between PNVCL and PNVCL-AuNP nanogel dispersions. As simple ionic solutions heat in oscillating electric field, the conductivity difference between PNVCL and PNVCL-AuNP nanogel samples needed to be studied to exclude the possibility of different ion concentration, causing the difference of the heatability of PNVCL-AuNPs and PNVCL nanogels. Thus the conductivity was measured with ZetaSizer for the samples and was $0.346 \mathrm{mS} / \mathrm{cm}$ for PNVCL nanogel and 0.332 $\mathrm{mS} / \mathrm{cm}$ for PNVCL-AuNPs. As the conductivity of the PNVCL nanogel dispersion is higher, we can conclude that AuNPs attached to the PNVCL nanogels can be used to sensitize the particles to heating via $R F$ radiation (oscillating electric field). 

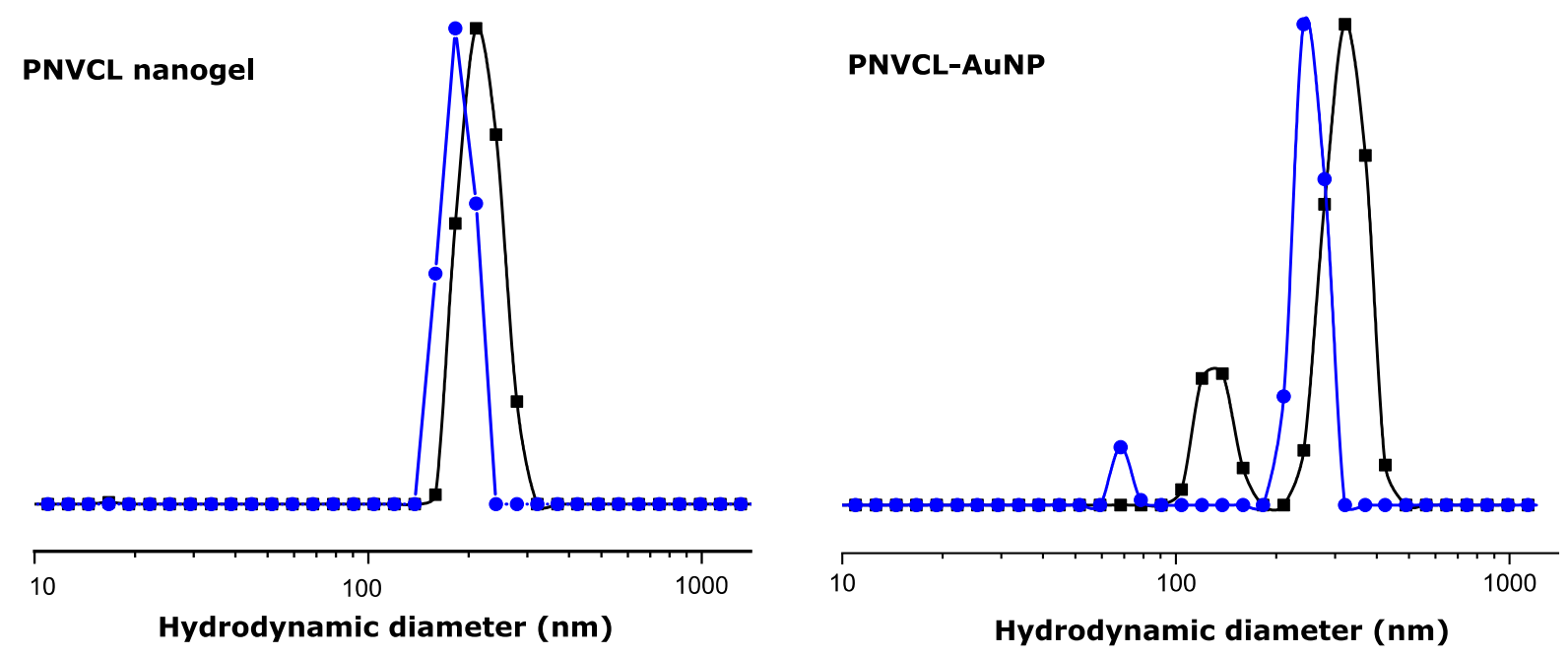

Figure 11. Hydrodynamic radius before (घ) and after (•) 5 min RF exposure for nanogels; PNVCL on left and for PNVCL-AuNP on right.

\section{Interactions of the nanogels with low molecular mass organic compounds}

Interactions of the nanogels with organic substances of varying water solubilities were studied using two fluorescent dyes. ANS is a water-soluble, negatively charged amphiphilic dye, which has a weak fluorescence emission in a polar environment and a much stronger emission in less polar environments (100-fold increase in quantum yield when water is replace with ethanol).[52] Also the position of the emission maximum is sensitive to polarity, and a blue shift is observed when polarity of the environment decreases (the position of peak emission maximum is $50 \mathrm{~nm}$ lower in ethanol compared to $\mathrm{H}_{2} \mathrm{O}$ ). ANS has been used to probe the hydrophobic domains in proteins and membranes,[52-54] hydrogels,[55] and to follow the phase transitions of thermoresponsive polymers as PDMEAMA,[56] PNIPAm-b-PIL[57] and PEO-b-PNIPAm[58].

Results of the fluorescence studies with ANS are presented in Figures 12 and 13. A solution of linear PNVCL was studied first. The fluorescence emission of ANS from the polymer solution was relatively high already at temperatures below $30^{\circ} \mathrm{C}$, as the probe interacted with the solvated polymer and was in a less polar environment compared to the pure buffer. Upon heating the polymer collapses to globules/aggregates and the probe binds to the dehydrated parts of the polymer. During heating from $31^{\circ} \mathrm{C}$ to $41^{\circ} \mathrm{C}$, the emission intensity increased by 3-fold, and the position of emission maximum was blue shifted $6 \mathrm{~nm}$ as ANS diffused into less polar pockets in the polymer. Further heating resulted in a 
decrease of emission intensity, because ANS was pushed out from the compressing PNVCL globules/aggregates. No precipitation of the polymer was observed in a light scattering experiment of the sample.

The fluorescence emission of ANS from PNVCL nanogel dispersion was high already at low temperature indicating that ANS was in a non-polar environment i.e inside the nanogels. Upon heating, the intensity of emission started to decrease above $34^{\circ} \mathrm{C}$, evidently because ANS was pushed out from the shrinking nanogels. According to dynamic light scattering studies the volume phase transition was complete at $55^{\circ} \mathrm{C}$ (Figure 5). The release of ANS was, however, observed to continue through the whole measuring temperature range, up to $73^{\circ} \mathrm{C}$.

The fluorescence emission of ANS from the PNVCL-AuNPs dispersion was low at all temperatures because the AuNPs quench the fluorescence. Quenching of the fluorescence of dye molecules by AuNPs is a well-known phenomenon and has been utilized in fluorescence based sensors. [59] However, the fluorescence intensity of ANS in PNVCL-AuNPS dispersion is dependent of temperature, as is seen in Figure 12B. Above $37^{\circ} \mathrm{C}$ the emission decreases as function of temperature until it reaches the intensity of the probe in pure buffer at $68^{\circ} \mathrm{C}$. The emission maximum also clearly redshifts closer to the value of the probe in the buffer, see Figure 13. Thus, we conclude that the release of ANS from PNVCL-AuNPs proceeds to a greater extent compared to the release from the neat PNVCL nanogel. The negatively charged AuNPs seem to repel the anionic probe from the nanogel surface.

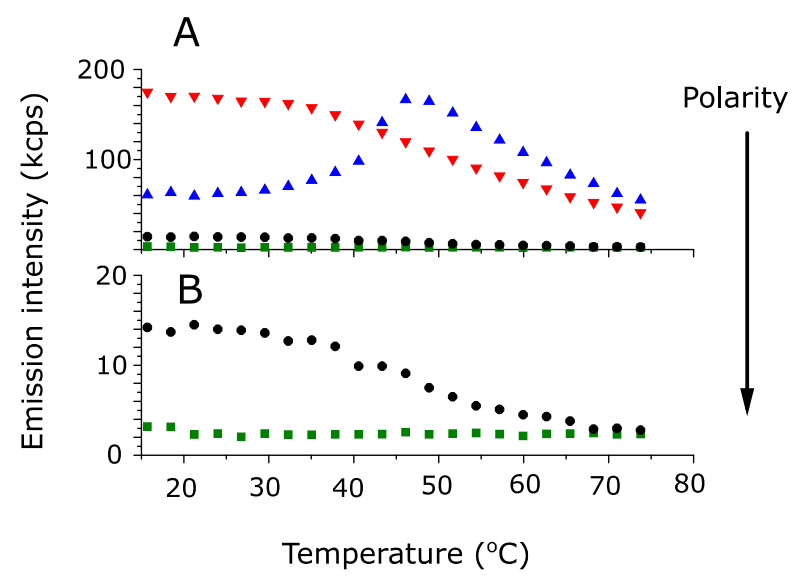

Figure 12. Fluorescence emission of ANS in 10mM HEPES buffer (A) with $\square$ no polymer, $\boldsymbol{\Delta}$ Linear PNVCL, $\nabla$ PNVCL nanogel and $\bullet$ PNVCL-AuNPs. B shows higher magnification for $\square$ no polymer and PNVCL-AuNPs. 


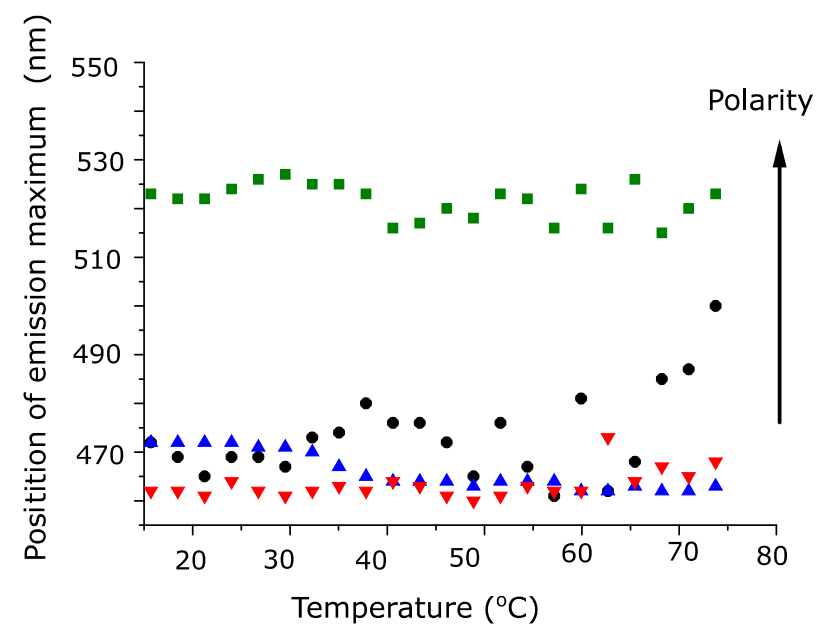

Figure 13. Wavelength of the fluorescence emission maxima of ANS in 10mM HEPES buffer with no polymer, $\triangle$ Linear PNVCL, $\nabla$ PNVCL nanogel and PNVCL-AuNPs.

Solutions and dispersions were also studied with a hydrophobic, sparingly water soluble non-charged fluorescence probe, 4HP. This probe is known to be sensitive to the viscosity and polarity of its surroundings.[60] Increasing the polarity of a solution leads to a redshift of the fluorescence emission maximum and to an increase in the quantum yield. Increasing viscosity has been shown to lead to a blueshift of emission maximum and to an increase in quantum yield. The shift in emission maximum has been used as indicator of solvent polarity in thin films doped with polar solvents.[61] The emission enhancement, (increase in quantum yield) has been used to follow polymerization processes as viscosity increases in the process and this can be detected from emission intensity.[62,63]

The fluorescence emission intensity of 4HP in a solution of linear PNVCL (Figure 14) is at a low level below $34^{\circ} \mathrm{C}$ as $4 \mathrm{HP}$ is in an aqueous, polar, low viscosity environment. Above $34{ }^{\circ} \mathrm{C}$, the polymer collapses in to assemblies, leading to an increase of the emission intensity with a blueshift of the emission maximum (Figure 15). The changes in fluorescence emission are related to an increase in viscosity of the surroundings of the probe. The probe is also expected to be in less polar environment after the collapse of the polymer. This is expected to result in decreased emission intensity. However, obviously the increase in viscosity had a higher impact on the fluorescence compared to the decrease in polarity, as an increase in emission intensity was observed upon heating. The fluorescence emission intensity reaches a plateau level at $65^{\circ} \mathrm{C}$. After this point viscosity does not increase 
anymore. No sign of the probe being pushed out from the collapsed polymer to aqueous phase i.e decrease in intensity, was observed.

The fluorescence emission intensity of 4HP in the PNVCL nanogel was high already at room temperature owing to the highly viscous gel surroundings of the probe. Upon heating, there was a very moderate decrease in emission intensity. The position of emission maximum, shown in Figure 13 was also very stable upon heating. The surroundings of $4 \mathrm{HP}$ were evidently stable and unchanged upon heating, i.e 4HP binds to the viscous, hydrophobic pockets inside the gel.

The fluorescence of 4HP from PNVCL-AuNP dispersion was low at all temperatures due to the fluorescence quenching by AuNPs. Still, the emission intensity against temperature had same features as with the neat PNVCL nanogels. The non-charged probe with low water solubility did not detect differences in the thermal behavior of PVCL nanogels and PVCL-AuNPs.

Fluorescence anisotropy measurements were performed on 4HP in PNVCL and PNVCL-AuNP nanogel dispersions to study the effect of viscosity without a contribution of polarity. Anisotropy measurements give information on the depolarization of light that is caused by the movement of the probe between excitation and emission.[64] Increase in anisotropy indicates an increase in the local friction experienced by the dye. The fluorescence anisotropy of 4HP increased upon heating in both samples indicating increased restraint on movement. Notably, anisotropy was higher with neat PNVCL nanogel at all temperatures. The accuracy of the measurements may suffer from the light scattering effects, however, in the present case the anisotropy difference between two samples may owe to structural differences. As was shown in Figure 5, the neat nanogels are less swollen than those decorated with AuNPs. The increase of anisotropy with temperature suggests that the fluorescent probe molecules inside the nanogel are more tightly bound upon heating. Because of this they are not released to the surrounding water. 


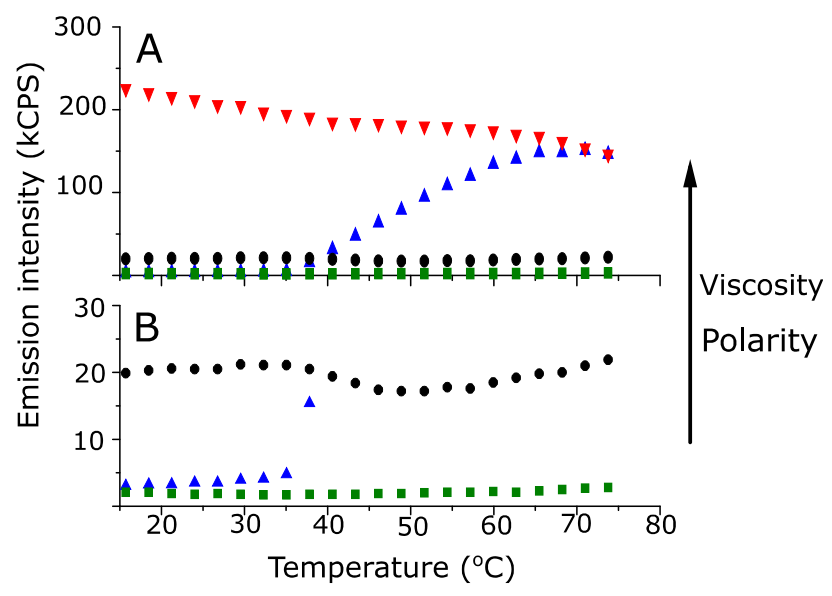

Figure 14. Fluorescence emission of 4HP in 10mM HEPES buffer(A) with $\square$ no polymer, $\Delta$ linear PNVCL, $\nabla$ PNVCL gel and $P N V C L-A u N P s .(B)$ is a magnification of the data in $(A)$.

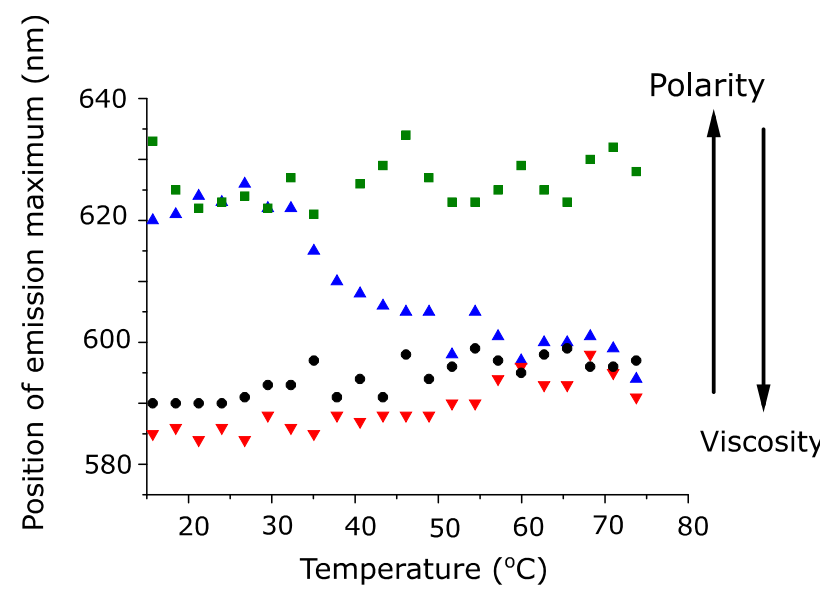

Figure 15. Position of fluorescence emission maxima of 4HP in 10mM HEPESPBS buffer with $\square$ no polymer, $\triangle$ Linear PNVCL, $\nabla$ PNVCL gel and - PNVCL-AuNPs. 


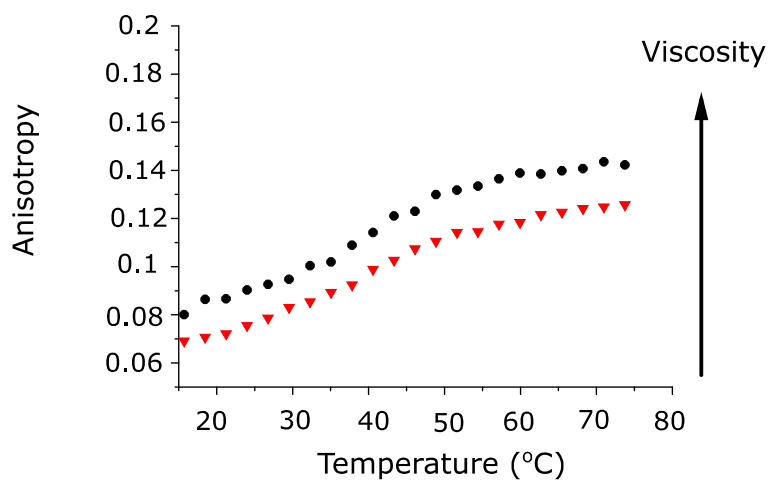

Figure 16. Anistropy measurements for $4 \mathrm{HP}$ in a dispersion of nanogels; $\nabla$ PNVCL and $\bullet$ PNVCLAuNPs

\section{Conclusions}

Soft PNVCL nanogels with propargyl functionalities, were synthesized via precipitation polymerization. The nanogels had crosslinked cores and less crosslinked shells. The surface layers (shell) of the nanogels were decorated with gold nanoparticles. More precisely, azide functional AuNPs $(2.8 \mathrm{~nm})$ were bound to the gels via click reactions (CUAAC). Cryo-TEM imaging and IR confirmed the attachment of AuNPs to the PNVCL nanogels. Hydrodynamic diameter distribution became bimodal after AuNPs were connected to the nanogels and the average diameter increased. Owing to the acidic groups on both the nanogel and on the AuNPs the nanogels were colloidally stable at all temperatures. AuNPs sensitized the hybrid particles to light and radiofrequency radiation, and the nanogels shrank upon exposure. However, it was seen that the irradiation of the AuNPs did not heat the nanogels homogeneously, smaller nanogels shrank relatively more than the big ones. Fluorescence spectroscopy was used to verify the applicability of the nanogels as hosts for low molecular mass organic compounds. Of the two fluorescence probes the one with negative charge and higher water solubility (ANS) was released partly from the linear PNVCL and the neat nanogel upon heating from 35 to $73^{\circ} \mathrm{C}$. The release proceeded to greater extent with PNVCL-AuNPs due to the negative charges on the AuNPs. The more hydrophobic non-charged dye $(4 \mathrm{HP})$ was not released from the linear polymer nor from the nanogels. 


\section{Acknowledgements}

Dr. Sami-Pekka Hirvonen is acknowledged for his contribution in designing and assembling the setup for the RF-heating experiments.

\section{References}

[1] H. Vihola, A. Laukkanen, L. Valtola, H. Tenhu, J. Hirvonen, Cytotoxicity of thermosensitive polymers poly $(\mathrm{N}$-isopropylacrylamide $)$, poly(N-vinylcaprolactam) and amphiphilically modified poly $(\mathrm{N}$ vinylcaprolactam). Biomater. 26, (2005), 3055-3064, https://doi.org/10.1016/j.biomaterials.2004.09.008.

[2] S. Bian, J. Zheng, X. Tang, D. Yi, Y. Wang, W. Yang. One-Pot Synthesis of Redox-Labile Polymer Capsules via Emulsion Droplet-Mediated Precipitation Polymerization. Chem. Mater. 27 (2015), 12621268, https://pubs.acs.org/doi/10.1021/cm5042315.

[3] M.A. González-Ayón, J. A. Sañudo-Barajas, L. A. Picos-Corrales, A. Licea-Claverie. PNVCLPEGMA nanohydrogels with tailored transition temperature for controlled delivery of 5-fluorouracil. J Polym Sci Part A: Polym Chem, 53, (2015), 2662-2672, http://dx.doi.org/10.1002/pola.27766.

[4] V. Kozlovskaya, F. Liu, B. Xue, F. Ahmad, A. Alford, M. Saeed, E. Kharlampieva. Polyphenolic Polymersomes of Temperature-Sensitive Poly(N-vinylcaprolactam)-block-Poly(N-vinylpyrrolidone) for Anticancer Therapy. Biomacromolecules, 18 (2017) 2552-2563, pubs.acs.org/doi/10.1021/acs.biomac.7b00687

[5] S. Lou, S. Gao, W. Wang, M. Zhang, Q. Zhang, C. Wang, C. Li, D. Kong. Temperature/pH dual responsive microgels of crosslinked poly( $\mathrm{N}$-vinylcaprolactam-co-undecenoic acid) as biocompatible materials for controlled release of doxorubicin. J Appl Polym Sci, 131, (2014), http://dx.doi.org/10.1002/app.41146.

[6] K. Madhusudana Rao, B. Mallikarjuna, K. S. V. Krishna Rao, S. Siraj, K. Chowdoji Rao, M.C.S. Subha. Novel thermo/pH sensitive nanogels composed from poly(N-vinylcaprolactam) for controlled release of an anticancer drug. Colloids Surf B; 102 (2013), 891-897 https://dx.doi.org/10.1016/j.colsurfb.2012.09.009

[7] N. S Rejinold, R.G Thomas, M. Muthiah, K.P. Chennazhi, I. Park, Y.Y. Jeong, K. Manzoor, R. Jayakumar. Radio frequency triggered curcumin delivery from thermo and $\mathrm{pH}$ responsive nanoparticles containing gold nanoparticles and its in vivo localization studies in an orthotopic breast tumor model. RSC Adv; 4, (2014), 39408-3942, http://dx.doi.org/10.1039/C4RA05727A.

[8] N. S. Rejinold, M. Muthunarayanan, V.V. Divyarani, P.R. Sreerekha, K.P. Chennazhi, S.V. Nair, H. Tamura, R. Jayakumar, Curcumin-loaded biocompatible thermoresponsive polymeric nanoparticles for cancer drug delivery. J Colloid Interface Sci; 360, (2011), 39-51

https://dx.doi.org/10.1016/j.jcis.2011.04.006 
[9] K. Sudhakar, K. Madhusudana Rao, M Subha, K. Chowdoji Rao, E. Rotimi Sadiku. Development of dual responsive 5-fluorouracil loaded poly(N-vinylcaprolactam) based nanogels for targeted drug delivery applications. Polym. Sci. Ser. B; 57, (2015), 638-644

https://link.springer.com/article/10.1134/S1560090415060160\#enumeration

[10] Y. Wang, J. Nie, B. Chang, Y. Sun, W. Yang. Poly(vinylcaprolactam)-Based Biodegradable Multiresponsive Microgels for Drug Delivery. Biomacromolecules;14 (2013):3034-3046 https://pubs.acs.org/doi/10.1021/bm401131w

[11] H. Vihola, A. Laukkanen, J. Hirvonen, H. Tenhu, Drug release characteristics of physically crosslinked thermosensitive poly(N-vinylcaprolactam) hydrogel particles. J. Pharm. Sci. 97 (2008), 47834793, https://doi.org/10.1002/jps.21348

[12] H. Vihola, A. Laukkanen, J. Hirvonen, H. Tenhu, Binding and release of drugs into and from thermosensitive poly( N-vinyl caprolactam) nanoparticles, Eur. J. Pharm. Sci. 16, (2002), 69-74 https://doi.org/10.1016/S0928-0987(02)00076-3

[13] NA Cortez-Lemus, A Licea-Claverie. Poly(N-vinylcaprolactam), a comprehensive review on a thermoresponsive polymer becoming popular. Prog. Polym. Sci. 53, (2016), 1-51, https://dx.doi.org/10.1016/j.progpolymsci.2015.08.001.

[14] V. Aseyev, S. Hietala, A. Laukkanen, M. Nuopponen, O. Confortini, F.E. Du Prez, H. Tenhu. Mesoglobules of thermoresponsive polymers in dilute aqueous solutions above the LCST. Polym. 46 (2005), 7118-7131, https://doi.org/10.1016/j.polymer.2005.05.097

[15] A. Laukkanen, L. Valtola, F.M. Winnik, H. Tenhu. Formation of Colloidally Stable Phase Separated Poly(N-vinylcaprolactam) in Water: A Study by Dynamic Light Scattering, Microcalorimetry, and Pressure Perturbation Calorimetry. Macromolecules, 37, (2004), 2268-2274 http://dx.doi.org/10.1021/ma035124l.

[16] A. Imaz, J. Forcada. N-vinylcaprolactam-based microgels: Synthesis and characterization. J. Polym. Sci. Part A: Polym. Chem. 46, (2008), 2510-2524 http://dx.doi.org/10.1002/pola.22583.

[17] A. Imaz, J. Forcada. N-vinylcaprolactam-based microgels: Effect of the concentration and type of cross-linker. J Polym Sci A Polym Chem; 46 (2008), 2766-2775, http://dx.doi.org/10.1002/pola.22609.

[18] A. Imaz, J. Forcada. Optimized buffered polymerizations to produce N-vinylcaprolactam-based microgels. Eur. Polym. J. 45 (2009), 3164-3175 https://doi.org/10.1016/j.eurpolymj.2009.08.003

[19] A. Imaz, J. Forcada. N-vinylcaprolactam-based microgels for biomedical applications. J. Polym. Sci. Part A: Polym. Chem. 48 (2010), 1173-1181, http://dx.doi.org/10.1002/pola.23876.

[20] A. Laukkanen, S. Hietala, S.L. Maunu, H. Tenhu, Poly(N-vinylcaprolactam) Microgel Particles Grafted with Amphiphilic Chains. Macromolecules;33 (2000):8703-8708, http://dx.doi.org/10.1021/ma000953h.

[21] F. Schneider, A. Balaceanu, A. Feoktystov, V. Pipich, Y. Wu, J. Allgaier, W. Pyckhout-Hintzen, A. Pich, G.J. Schneider. Monitoring the Internal Structure of Poly(N-vinylcaprolactam) Microgels with Variable Cross-Link Concentration. Langmuir, 30 (2014), 15317-15326, http://dx.doi.org/10.1021/la503830w 
[22] L. Paasonen, T. Laaksonen, C. Johans, M. Yliperttula, K. Kontturi, A Urtti. Gold nanoparticles enable selective light-induced contents release from liposomes. J Controlled Release;122 (2007):8693, https://doi.org/10.1016/j.jconrel.2007.06.009

[23] C.B. Collins, R.S. McCoy, B.J. Ackerson, G.J. Collins, C.J. Ackerson. Radiofrequency heating pathways for gold nanoparticles. Nanoscale;6 (2014):8459-8472 http://dx.doi.org/10.1039/C4NR00464G

[24] P. Pantano, C.D. Harrison, J. Poulose, D. Urrabazo, T.Q. Norman, E.I. Braun, R.K. Draper, L.J. Overzet. Factors affecting the 13.56-MHz radio-frequency-mediated heating of gold nanoparticles. Applied Spectroscopy Reviews (2017), 1-16 http://dx.doi.org/10.1080/05704928.2017.1314299

[25] J. Xie, S. Lee, X. Chen. Nanoparticle-based theranostic agents. Adv Drug Deliv Rev; 62 (2010), 1064-1079 https://doi.org/10.1016/j.addr.2010.07.009

[26] J.F. Hainfeld, D.N. Slatkin, T.M. Focella, H.M. Smilowitz. Gold nanoparticles: a new X-ray contrast agent. Br. J. Radiol. 79 (2006), 248-253, https://doi.org/10.1259/bjr/13169882

[27] L. Etchenausia, A. Khoukh, E. D. Lejeune, M. Save, RAFT/MADIX emulsion copolymerization of vinyl acetate and $\mathrm{N}$-vinylcaprolactam: towards waterborne physically crosslinked thermoresponsive particles, Polym. Chem. 8, (2017), 2244-2256, https://doi.org/10.1039/C7PY00221A

[28] F. Jasinski, V. L. Teo, R. P. Kuchel, M. M. Mballa, S. C. Thickett, R. H. G. Brinkhuis, W. Weaver, P. B. Zetterlund, J. Polym. Sci, part A: Polym. Chem. 55, (2017), 2513-2526, https://doi.org/10.1002/pola.28644

[29] R. Farley, B.R. Saunders. A general method for functionalisation of microgel particles with primary amines using click chemistry, Polym. 55 (2014), 471-480,

https://doi.org/10.1016/j.polymer.2013.12.022

[30] P. Rungta, Y.P. Bandera, V. Tsyalkovsky, S.H. Foulger. Designing fluoroprobes through Forster resonance energy transfer: surface modification of nanoparticles through "click" chemistry. Soft Matter, 6 (2010), 6083-6095, http://dx.doi.org/10.1039/C0SM00470G

[31] J. Kim, B.W. Boote, J.A. Pham, J. Hu, H. Byun. Thermally tunable catalytic and optical properties of gold-hydrogel nanocomposites. Nanotechnology, 23 (2012), 275606, https://doi.org/10.1088/0957$4484 / 23 / 27 / 275606$

[32] S. Shi, L. Zhang, T. Wang, Q. Wang, Y. Gao, N. Wang. Poly(N-isopropylacrylamide)-Au hybrid microgels: synthesis, characterization, thermally tunable optical and catalytic properties. Soft Matter, 9 (2013), 10966-10970, http://dx.doi.org/10.1039/C3SM52303A

[33] H. Jia, D. Schmitz, A. Ott, A. Pich, Y. Lu. Cyclodextrin modified microgels as "nanoreactor" for the generation of Au nanoparticles with enhanced catalytic activity. J Mater Chem A, 3 (2015), 6187-6195, http://dx.doi.org/10.1039/C5TA00197H.

[34] L. Hou, P. Wu. The effect of added gold nanoparticles on the volume phase transition behavior for PVCL-based microgels. RSC Adv, 4 (2014), 39231-39241, http://dx.doi.org/10.1039/C4RA06471B 
[35] M.J. Hostetler, J.E. Wingate, C. Zhong, J.E. Harris, R.W. Vachet, M.R. Clark, J.D. Londono, S.J. Green, J.J. Stokes, G.D. Wignall, G.L. Glish, M.D. Porter, N.D. Evans, R.W. Murray. Alkanethiolate Gold Cluster Molecules with Core Diameters from 1.5 to $5.2 \mathrm{~nm}$ : Core and Monolayer Properties as a Function of Core Size. Langmuir, 14 (1998), 17-30, http://dx.doi.org/10.1021/la970588w

[36] M. Biswas, E. Dinda, M.H. Rashid, T.K. Mandal. Correlation between catalytic activity and surface ligands of monolayer protected gold nanoparticles. J. colloid and interface sci. 368 (2012),77-85 https://doi.org/10.1016/j.jcis.2011.10.078

[37] S.V. Jenkins, S. Chen, J Chen. Gold-copper alloyed nanorods for metal-catalyzed organic reactions: implication of surface ligands on nanoparticle-based heterogeneous catalysis. Tetrahedron Letters, 56 (2015), 3368-3372, https://doi.org/10.1016/j.tetlet.2015.03.041.

[38] S. Berger, R. Singh, J. D.Sudha, H. Adler, A. Pich, Microgel/clay nanohybrids as responsive scavenger systems, Polymer, 51, (2010), 3829-3835, https://doi.org/10.1016/j.polymer.2010.06.039

[39] W. Sun, P. Wu, The structure and volume phase transition behavior of poly(N-vinylcaprolactam)based hybrid microgels containing carbon nanodots, Phys. Chem. Chem. Phys., 2017,19, 127-134, DOI:10.1039/C6CP06862F

[40] K. Wiemer,a K. Dörmbach,b I. Slabu,c G. Agrawal,b F. Schrader,a T. Caumanns,d S. D. M. Bourone,a J. Mayer,d J. Steitz,e U. Simona and A. Pich*b, "Hydrophobic superparamagnetic FePt nanoparticles in hydrophilic poly(N-vinylcaprolactam) microgels: a new multifunctional hybrid system", J. Mater. Chem. B, 2017,5, 1284-1292, DOI: 10.1039/C6TB02342H

[41] L. Shen, A. Pich D. Fava, M. Wang, S. Kumar, C. Wu, G.D. Scholes, and M. A. Winnik, "Loading quantum dots into thermo-responsive microgels by reversible transfer from organic solvents to water" J. Mater. Chem., 2008,18, 763-770, DOI: 10.1039/B713253K

[42] Y. Lin, S. Tsai, S.J. Yu. Highly Efficient and Recyclable Au Nanoparticle-Supported Palladium(II) Interphase Catalysts and Microwave-Assisted Alkyne Cyclotrimerization Reactions in lonic Liquids. J Org Chem, 73 (2008), 4920-4928, http://dx.doi.org/10.1021/jo800524h.

[43] S. Pal, M.R. Hill, B.S. Sumerlin. Doubly-responsive hyperbranched polymers and core-crosslinked star polymers with tunable reversibility. Polym. Chem. 6 (2015), 7871-7880, http://dx.doi.org/10.1039/C5PY01295C

[44] A.C. Templeton, M.J. Hostetler, C.T. Kraft, R.W. Murray. Reactivity of Monolayer-Protected Gold Cluster Molecules: Steric Effects. J. Am. Chem. Soc. 120 (1998),1906-1911, http://dx.doi.org/10.1021/ja973863+

[45] S. Kozanoğlu, T. Özdemir, A. Usanmaz. Polymerization of N-Vinylcaprolactam and Characterization of Poly(N-Vinylcaprolactam). J. Macromol. Sci. A. 48 (2011), 467-477, http://dx.doi.org/10.1080/10601325.2011.573350.

[46] R.L. Whetten, J.T. Khoury, M.M. Alvarez, S. Murthy, I. Vezmar, Z.L. Wang, P.W. Stephens, C.L. Cleveland, W.D. Luedtke, U. Landman. Nanocrystal gold molecules. Adv. Mater. 8 (1996), 428-433, https://doi.org/10.1002/adma.19960080513. 
[47] R.L. Whetten, M.N. Shafigullin, J.T. Khoury, T.G. Schaaff, I. Vezmar, M.M. Alvarez, A. Wilkinson. Crystal Structures of Molecular Gold Nanocrystal Arrays, Acc. Chem. Res. 32 (1999), 397-406, https://doi.org/10.1021/ar970239t

[48] P. Pulkkinen, Nanoparticles of Gold and Copper: Sintering and Supramolecular Assembly Investigations, (2014), URN: ISBN:978-952-10-9949-6, http://urn.fi/URN:ISBN:978-952-10-9949-6

[49] C. Noguez. Surface Plasmons on Metal Nanoparticles: The Influence of Shape and Physical Environment. J. Phys. Chem. C. 111(2007), 3806-3819, https://doi.org/10.1021/jp066539m.

[50] W. Haiss, N.T.K. Thanh, J. Aveyard, D.G. Fernig. Determination of Size and Concentration of Gold Nanoparticles from UV-Vis Spectra. Anal. Chem. 79 (2007), 4215-4221, http://dx.doi.org/10.1021/ac0702084.

[51] C.B. Collins, M.A. Tofanelli, S.D. Noblitt, C.J. Ackerson. Electrophoretic Mechanism of Au25(SR)18 Heating in Radiofrequency Fields. J. Phys. Chem. Lett. 9 (2018), 1516-1521, https://doi.org/10.1021/acs.jpclett.8b00327.

[52] J. Slavík. Anilinonaphthalene sulfonate as a probe of membrane composition and function. Biochimica et Biophysica Acta (BBA) - Reviews on Biomembranes, 694 (1982), 1-25, https://doi.org/10.1016/0304-4157(82)90012-0

[53] D. Matulis, R. Lovrien. 1-Anilino-8-Naphthalene Sulfonate Anion-Protein Binding Depends Primarily on Ion Pair Formation. Biophys. J. 74 (1998), 422-429, https://doi.org/10.1016/S00063495(98)77799-9

[54] D .Matulis, C.G. Baumann, V.A. Bloomfield, R.E. Lovrien. 1-Anilino-8-naphthalene sulfonate as a protein conformational tightening agent. Biopolymers, 49 (1999), 451-458, https://doi.org/10.1002/(SICI)1097-0282(199905)49:6<451::AID-BIP3>3.0.CO;2-6

[55] M. Ricca, V. Foderà, D. Giacomazza, M. Leone, G. Spadaro, C. Dispenza. Probing the internal environment of PVP networks generated by irradiation with different sources. Colloid. Polym. Sci. 288 (2010), 969-980, http://dx.doi.org/10.1007/s00396-010-2217-7.

[56] J. Niskanen, M. Karesoja, T. Rossi, H. Tenhu. Temperature and $\mathrm{pH}$ responsive hybrid nanoclay grafted with PDMAEMA. Polym. Chem. 2 (2011), 2027-2036, http://dx.doi.org/10.1039/C1PY00143D.

[57] E. Karjalainen, N. Chenna, P. Laurinmaki, S.J. Butcher, H. Tenhu. Diblock copolymers consisting of a polymerized ionic liquid and poly( $\mathrm{N}$-isopropylacrylamide). Effects of PNIPAM block length and counter ion on self-assembling and thermal properties. Polym. Chem.4 (2013), 1014-1024, http://dx.doi.org/10.1039/C2PY20815F.

[58] P. Pramanik, S. Ghosh. Thermoresponsive polymersome from a double hydrophilic block copolymer. J. Polym. Sci. Part A: Polym. Chem. 53 (2015), 2444-2451, http://dx.doi.org/10.1002/pola.27735.

[59] D. Ghosh, N. Chattopadhyay. Gold and silver nanoparticles based superquenching of fluorescence: A review. Journal of Luminescence, 160 (2015), 223-232. https://www.sciencedirect.com/science/article/pii/S0022231314007236. 
[60] S.L Bondarev, V.N. Knyukshto, V.I. Stepuro, A.P. Stupak, A.A. Turban. Fluorescence and Electronic Structure of the Laser Dye DCM in Solutions and in Polymethylmethacrylate. J. App. Spect. 71 (2004),194-201, https://doi.org/10.1023/B:JAPS.0000032874.60100.a0.

[61] Y. Qin, P. Zhang, L. Lai, Z. Tian, S. Zheng, J. Lu. Luminous composite ultrathin films of the DCM dye assembled with layered double hydroxides and its fluorescence solvatochromism properties for polarity sensors. J Mater. Chem. C. 3 (2015): 5246-5252. DOI: 10.1039/C5TC00736D

[62] R. Vatanparast, S. Li, K. Hakala, H. Lemmetyinen. Monitoring of Curing of Polyurethane Polymers with Fluorescence Method. Macromolecules, 33 (2000), 438-443, http://dx.doi.org/10.1021/ma991414j.

[63] Z.J. Wang, J.C. Song, R. Bao, D.C. Neckers. Fluorescence probes for monitoring polymerization processes. J. Polym. Sci. Part B: Polym. Phy. 34 (1996), 325-333

http://dx.doi.org/10.1002/(SICI)1099-0488(19960130)34:23.0.CO;2-L.

[64] J.R. Lakowicz, Principles of fluorescence spectroscopy. New York: Kluwer Academic/Plenum, $1999,3^{\text {rd }}$ edition. 